SUPPORTING INFORMATION FOR :

\title{
Molecular interaction and energy transfer between human serum albumin and polyoxometalates
}

Guangjin Zhang ${ }^{1}$, Bineta Keita ${ }^{1}$, Jean-Claude Brochon ${ }^{2}$, Pedro de Oliveira ${ }^{1}$, Louis Nadjo ${ }^{1 *}$ Constantin T. Craescu ${ }^{3}$, Simona Miron ${ }^{3}$

1. Laboratoire de Chimie Physique,Equipe d' Electrochimie et Photoelectrochimie, UMR 8000, CNRS, Universite Paris-Sud, bâtiment 350, 91405 Orsay Cedex, France

2. Laboratoire de Biotechnologies et de Pharmacologie Génétique Appliquee, Ecole Normale Superieure de Cachan, 61 avenue de Président Wilson, 94235 Cachan cedex, France 3. INSERM U759/Institut Curie-Recherche, Centre Universitaire Paris-Sud, Bâtiment 112, 91405 Orsay Cedex, France

Table of Contents

1. Fig.SI1. Stern-Volmer plot of quenching of NATA's fluorescence by P5W30. page $\mathrm{S} 2$

2. Figure SI2. Plot of log kq vs $\mu^{1 / 2}$ for both systems page S3

3. Table SI1 and SI2: lifetimes of HSA as a function of increasing addition of P5W30 and $\mathrm{H} 2 \mathrm{~W} 12$ respectively page $\mathrm{S} 4$

4. Domain structure of HSA page $\mathrm{S} 5$

\footnotetext{
${ }^{1}$ To whom correspondence should be addressed: Email: nadjo@lcp.u-psud.fr, Tel: 33169157751 Fax: 33169154328
} 


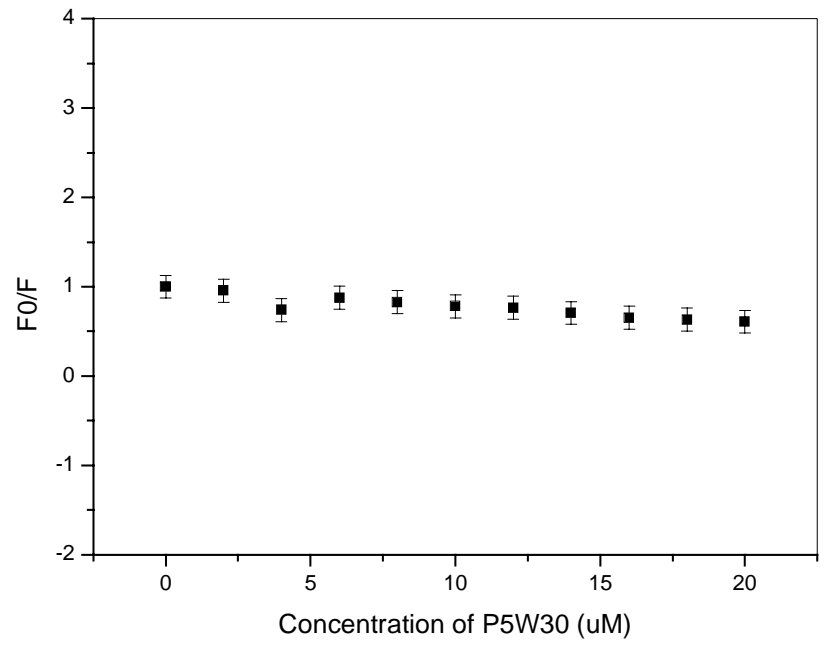

Fig. S1 Stern-Volmer plot of quenching of NATA's fluorescence by P5W30. The data were corrected for inner filter absorption effects of the POMs 

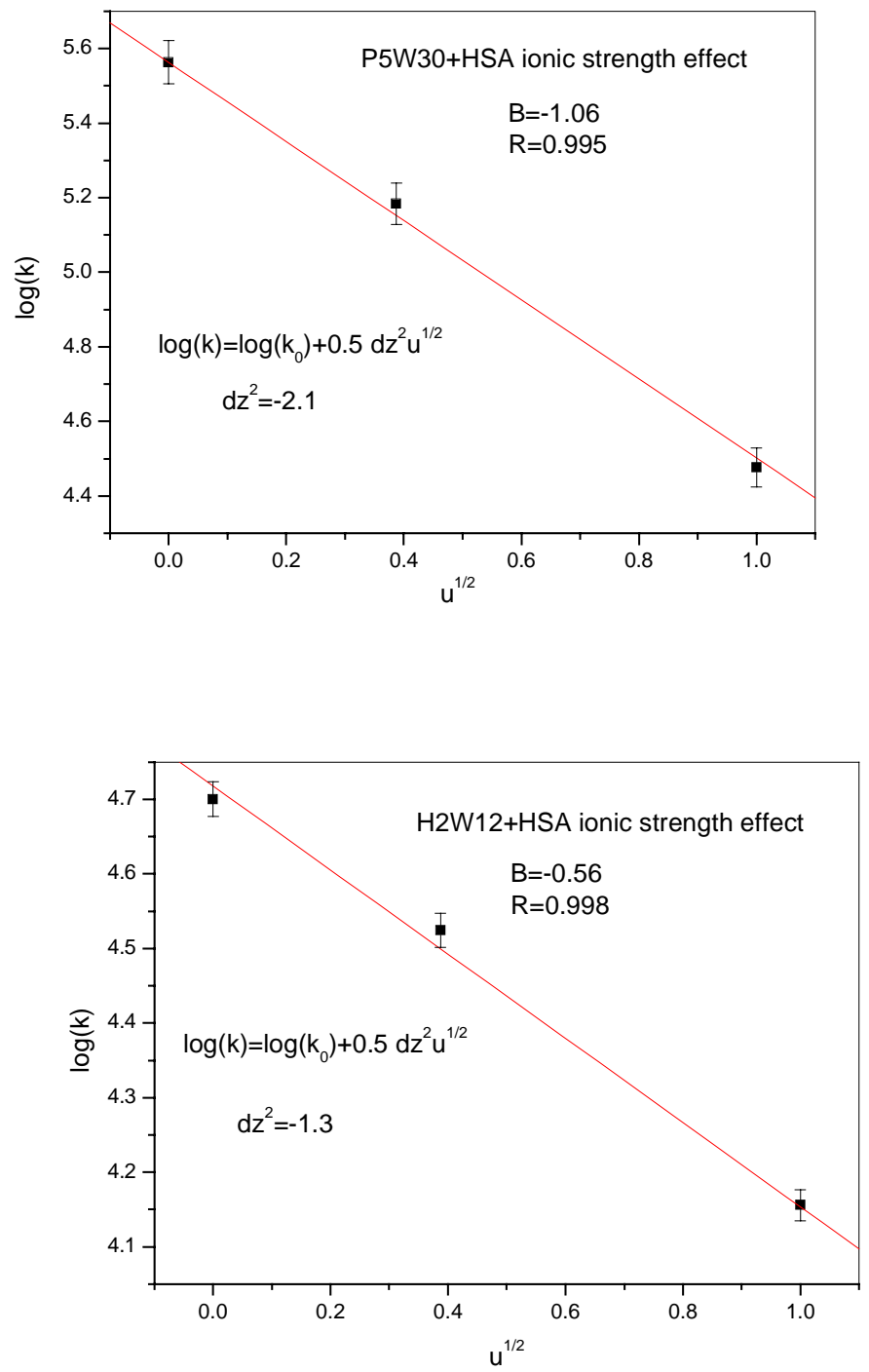

Figure SI1. Plot of logk vs $\mu^{1 / 2}$ for both systems 
Table SI 1. Lifetimes(ns) of HSA (10uM)as a function of increasing addition of P5W30.

\begin{tabular}{l|llllllllc}
\hline$\gamma=[\mathrm{POM}] /[\mathrm{HSA}]$ & $\begin{array}{l}\text { Tau1 } \\
\text { ns }\end{array}$ & $\begin{array}{l}\mathrm{c1} \\
(\%)\end{array}$ & $\begin{array}{l}\text { Tau2 } \\
\mathrm{ns}\end{array}$ & $\begin{array}{l}\mathrm{c2} \\
(\%)\end{array}$ & $\begin{array}{l}\text { Tau3 } \\
\mathrm{ns}\end{array}$ & $\begin{array}{l}\mathrm{c3} \\
(\%)\end{array}$ & $\begin{array}{l}\text { Tau4 } \\
\text { ns }\end{array}$ & $\begin{array}{l}\mathrm{c4} \\
(\%)\end{array}$ & $\begin{array}{c}<\text { Tau } \\
\text { ns }\end{array}$ \\
\hline 0 & 0.22 & 0.10 & 0.73 & 0.16 & 3.00 & 0.32 & 6.59 & 0.41 & 3.82 \\
0.4 & 0.222 & 0.19 & 0.72 & 0.21 & 2.86 & 0.26 & 6.61 & 0.34 & 3.21 \\
0.8 & 0.16 & 0.30 & 0.67 & 0.25 & 2.63 & 0.22 & 6.60 & 0.23 & 2.32 \\
1.2 & 0.166 & 0.38 & 0.67 & 0.26 & 2.28 & 0.18 & 5.85 & 0.15 & 1.76 \\
1.6 & 0.14 & 0.49 & 0.56 & 0.26 & 1.90 & 0.16 & 4.85 & 0.09 & 1.08 \\
2.0 & 0.12 & 0.50 & 0.45 & 0.25 & 1.10 & 0.11 & 2.22 & 0.10 & 0.77 \\
\hline
\end{tabular}

Table SI2. Lifetimes of HSA as a function of increasing addition of H2W12.

\begin{tabular}{l|lllllllll}
\hline$\gamma=[\mathrm{POM}] /[\mathrm{HSA}]$ & $\begin{array}{l}\text { Tau1 } \\
\text { ns }\end{array}$ & $\begin{array}{l}\mathrm{c1} \\
(\%)\end{array}$ & $\begin{array}{l}\text { Tau2 } \\
\mathrm{ns}\end{array}$ & $\begin{array}{l}\mathrm{c2} \\
(\%)\end{array}$ & $\begin{array}{l}\text { Tau3 } \\
\mathrm{ns}\end{array}$ & $\begin{array}{l}\mathrm{c3} \\
(\%)\end{array}$ & $\begin{array}{l}\text { Tau4 } \\
\mathrm{ns}\end{array}$ & $\begin{array}{l}\mathrm{c4} \\
(\%)\end{array}$ & $<$ Tau> \\
\hline 0 & & & 0.59 & 0.20 & 2.80 & 0.32 & 6.53 & 0.48 & 4.18 \\
0.5 & 0.17 & 0.08 & 0.62 & 0.20 & 2.76 & 0.32 & 6.41 & 0.42 & 3.68 \\
1 & 0.09 & 0.12 & 0.62 & 0.19 & 2.83 & 0.29 & 6.42 & 0.40 & 3.50 \\
2 & 0.13 & 0.13 & 0.61 & 0.23 & 2.68 & 0.29 & 6.41 & 0.35 & 3.18 \\
\hline
\end{tabular}




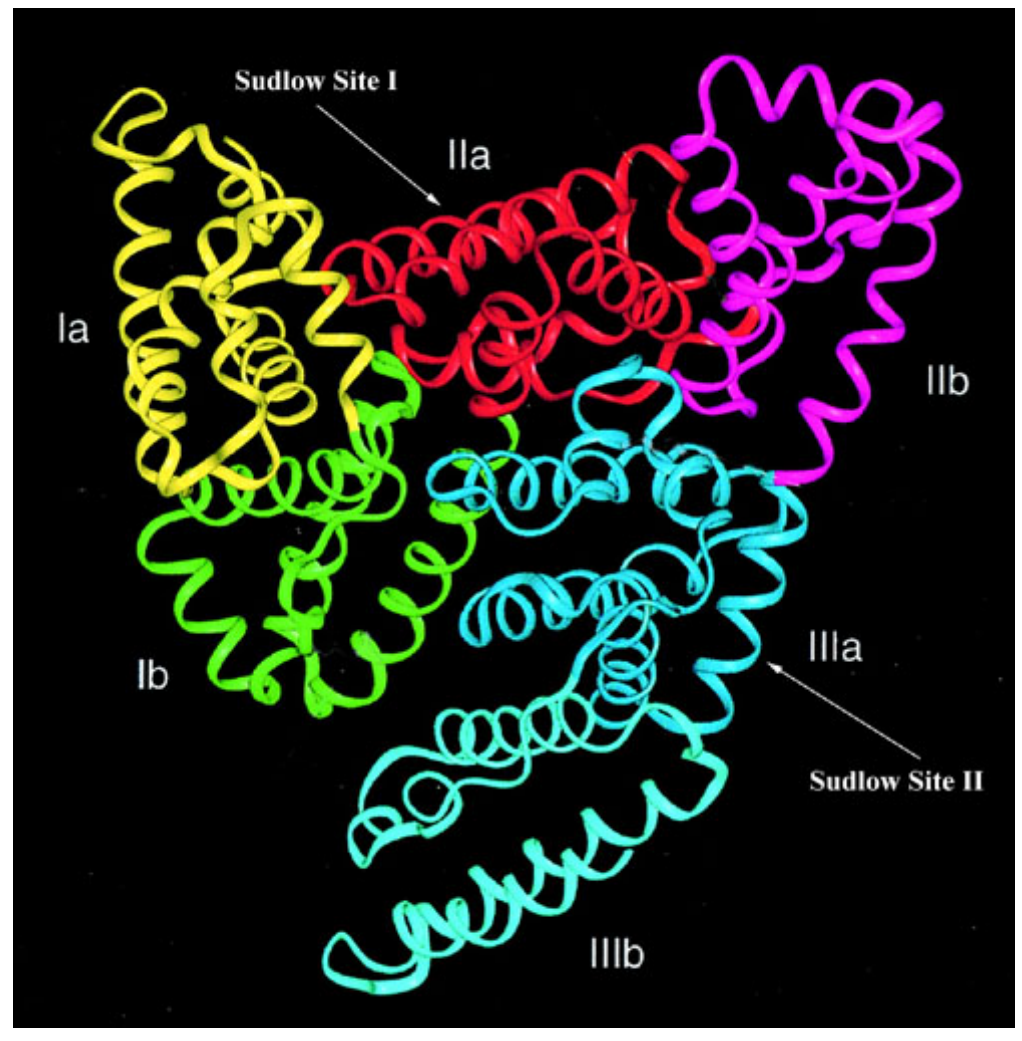

Fig.SI3 